\title{
Gender Differences and Affective Factors Influencing Mathematics Learning Success in an Enabling Program
}

\author{
Pek Foong Ng and Kung-Keat Teoh
}

\begin{abstract}
Mathematics learning and teaching is an area of interest to the teaching community in first year higher education and enabling programs due to the large gap of expected mathematics knowledge and the actual mathematics abilities of students in these programs with the goal of find solutions to bridge the gap of knowledge so that students can meet the expected knowledge required in a degree program of their choice. One of the factors of interest in the research community is the impact of gender on mathematics learning. This study investigates if there is a gender difference in terms of enabling students' mathematics achievement and affective factors related to mathematics, particularly, their self-efficacy, active learning strategies, perceived usefulness of mathematics, perception on learning environment that have an impact to their mathematics learning, achievement-oriented goals, enjoyment of mathematics, and mathematics anxiety based on a sample of 507 students undertaking an enabling program at a university in South Australia. Results indicated that male and female students' achievement in mathematics are statistically and significantly similar but male students scored higher in self-efficacy and enjoyment of learning mathematics while female students scored higher in mathematics anxiety. A discussion of the results and its implications are also presented.
\end{abstract}

Index Terms-Affective factors, mathematics learning, achievements, gender, enabling program.

\section{INTRODUCTION}

The affective domain plays an integral role in influencing the success of mathematics learning besides individual cognitive ability. Studies have shown that individual success in learning mathematics correlates with various affective factors such as self-efficacy, enjoyment of mathematics, perceived usefulness of mathematics, anxiety, proactive learning strategies, learning environment and motivation [1]-[4].

In Australia, the decline in the number of Australian students taking mathematics subjects in their final years of secondary school is concerning. The proportion of final year secondary school students with elementary level mathematics skills has increased by $30 \%$, while alarmingly those with intermediate level decreased by $22 \%$ and advanced level decreased by $27 \%$ from 1995 to 2007 [5]. This has been attributed to students' mathematics learning experience during their lower secondary school years, previous mathematics achievements, self-belief of their mathematics ability, interest and liking for higher level mathematics

Manuscript received August 17, 2018; revised December 4, 2018.

P. F. Ng is with University of South Australia, Adelaide South Australia 5001, Australia (e-mail: Jasmine.Ng@unisa.edu.au).

K. Teoh is with Flinders University, Adelaide, South Australia 5043, Australia (e-mail: teoh0036@flinders.edu.au). [subjects, and perceived usefulness of higher level mathematics [6]. As a result, many students are underprepared mathematically when entering university. In response, some of the universities in Australia provide mathematics pathways to support these students in their transition from school to university [7]. Similar scenario is seen in the United States education, a large proportion of college students are underprepared and the number of students with low mathematics skills and requiring remedial mathematics have risen considerably [8], [9].

The aim of this study is to examine the differences in mathematics achievement and contributing affective factors for male and female students in an enabling program at University of South Australia (UniSA), Australia. Tertiary enabling programs in Australia are widening participation programs that provide disadvantaged groups from low socio-economic status the opportunities to access tertiary education through an alternative pathway [10]. While many studies show that attitude toward mathematics affects achievement, studies on students taking mathematics in enabling programs in Australia is limited.

The study will focus on affective factors such as self-efficacy, active learning strategies, perceived usefulness of mathematics, learning environment, achievement-oriented goals, enjoyment and mathematics anxiety. The assumption of gender difference on affective factors is based on student mathematics results taken from one cohort of students from previous semester $(n=171)$ where female students $(M=54.53$, $S D=27.37)$ performed better than male students $(M=51.89$, $S D=26.13)$.

\section{AFFECTIVE FACTORS}

This study is formed based on affective factors found significant in previous research such as self-efficacy [11], [12], active learning strategies [13], perceived usefulness of mathematics [13], [14], learning environment [13], achievement-oriented goals [13]; [15]-[17], enjoyment [11], [18], and mathematics anxiety [18].

Self-efficacy refers to an individual's perceived ability to undertake mathematics learning activities. Reference [13] shows that individuals with high self-efficacy believe they are capable to learn irrespective of the difficulty level. The findings indicated that self-efficacy positively correlates with student achievements.

Active learning strategies refers to students' active use of variety of strategies to engage in successful mathematics learning. It refers to students' initiative to actively use different strategies to build new knowledge on what they learned previously, resulting in better test results [13]. 
Perceived usefulness of mathematics refers to student's perception on the usefulness and relevance of learning mathematics. Clanton found that project-based learning approach has significant positive change in students' enjoyment and perceived usefulness of mathematics [19].

Learning environment is students' perception of the external factors that may have an impact on their mathematics learning. Wang, Yin, Lu, and Zhang found that classroom environments that promote conducive classroom setting have significant and positive effects on students' affective aspects perceive value of learning mathematics [20].

Achievement oriented goals is students' perception of achievement and progress in learning. The motivation to learn is influenced by how students perceive achievement, often related to successful and satisfying experiences in learning and the need to improve their competence [21]. This motivation often requires students to be very goal or achievement oriented.

Enjoyment refers to students' enjoyment of the mathematics content and learning experience. Reference [22] shows that previous mathematics achievement correlates positively with enjoyment in mathematics classes. In short, students who enjoy learning mathematics tend to achieve better results than those who do not.

Mathematics anxiety is an individual's feelings of uneasiness and nervousness related to mathematics. Reference [23] defines mathematics anxiety as "a state of discomfort associated with performing mathematical tasks". In general, high levels of mathematics anxiety is negatively associated with the learning of mathematics.

\section{Methodology}

The participants comprise of 507 students with an almost equal number of male $(n=257)$ and female $(n=250)$ students studying enabling programs in one of the universities in South Australia. The age range of the participants is from 18 to $70(M=21.83, S D=6.22)$. Eighteen percent $(18 \%)$ of the participants indicated that their mathematics level is Year 10 and below while $31 \%$ of the participants indicated that they took mathematics up to Year 11. The result suggests that nearly half of the participants did not take Year 12 (highest level of secondary school) mathematics. The result is in line with Brown's report which shows that the proportion of Year 12 students whose mathematics is at advance level has dropped significantly [5].

A quantitative study using a survey approach was undertaken. A comprehensive literature review led to the development of a 5-point Likert scale instrument measuring seven identified affective factors. The items in the questionnaire were adopted and adapted from Students' Motivation Toward Science Learning scale [13], shortened version of Attitudes Toward Mathematics Inventory [14] and revised version of Fennema-Sherman Mathematics Anxiety Scale [18] to suit the students undertaking mathematics courses in the enabling program. We established seven factors in the questionnaire: self-efficacy (SE), active learning strategies (ALS), perceived usefulness of mathematics (PUM), learning environment (LE), achievement-oriented goals (AOG), enjoyment of mathematics (ENJ) and mathematics anxiety (MA). Two academics in mathematics reviewed the items to determine face validity of the instrument. Items were refined following the outcome of the review and 51 items were included in the instrument for pilot testing. A pilot test $(n=31)$ was conducted. Feedback was encouraged on items that the participants found confusing or unclear. Results from the pilot test show that the reliability coefficients, Cronbach alpha ranged from 0.71 to 0.93 , indicating the internal consistencies met the minimum threshold by Nunnally [24]. Thus, all the 51 items in the instrument were used for this study.

Ethics permission was obtained successfully from the university Ethics Committee. Data were collected from 974 students who undertook mathematics courses in an enabling program at UniSA coordinated by the researcher on a voluntary basis. Response rate was $53 \%$ whereby 517 students consented and provided responses. $2 \%$ of the responses which had substantial missing data were taken out prior to data analyses. Participants' grades were analysed to measure their mathematics achievement. IBM Statistical Package for the Social Sciences (SPSS) v23 was used to analyse the results.

\section{RESUlts AND Discussions}

The internal consistency of each factor was estimated with Cronbach alpha results are ranging from 0.73 to 0.921 , meeting the threshold of greater than 0.7 recommended by Nunnally, meeting reliability criteria [24]. Therefore, the questionnaire used was reliable.

When comparing students' achievement, results show that while the mean score for male students is higher than female students, the difference is not statistically significant; male students score $(M=56.44, S D=27.21)$ and female students $[M=53.78, S D=27.63 ; t(464)=1.05, p=0.30]$. This result contradicts the findings from Hughes-Isley where the researcher found statistical significant difference in achievement between male and female students taking remedial mathematics [25]. However, the result of this study is consistent with the recent meta-analyses study which shows no significant difference in achievement between female and male students across different grade levels in schools [26]. This could be due to the changes in stereotyping gender to specific domain of study in recent years.

An independent samples $t$-test was performed to compare the mean consistency scores of male and female students for each factor. Table I showed that there were statistically significant differences between male and female students for $\mathrm{SE}(p<0.001)$, ENJ $(p<0.05)$ and MA $(p<0.001)$ factors but no difference for ALS, PUM, LE and AOG factors.

The results of this study indicated that there was a significant difference in self-efficacy (SE) scores where male students scored higher $(M=3.47, S D=0.69)$ than female students $[(M=3.11, S D 0.77) ; t(485)=-5.48, p<0.001)]$. The calculated effect size is 0.5 which is moderate [27]. The result suggests that male students believe in their ability to work on mathematics task more than female students. This result 
supports the findings from a study which showed that while female students scored higher in self-efficacy related to language and arts than male students, male students tend to exhibit higher self-efficacy than their counterpart in mathematics [28]. Female students' lower self-efficacy has become an obstacle for them to advance in the mathematics related discipline [28], [29]. The result of this study suggests that more encouragement related activities in class may help female students to thrive better in learning mathematics.

TABLE I: INDEPENDENT SAMPLES T-TEST RESULTS

\begin{tabular}{llllll}
\hline \hline Factors & $M$ & $S D$ & $t$ & $d f$ & $p$ \\
\hline SE & & & -5.48 & 485 & $<0.001$ \\
$\quad$ Males & 3.47 & 0.69 & & & \\
$\quad$ Females & 3.11 & 0.77 & & & \\
ALS & & & 1.43 & 505 & 0.15 \\
$\quad$ Males & 3.90 & 0.52 & & & \\
$\quad$ Females & 3.96 & 0.45 & & & \\
PUM & & & 0.91 & 505 & 0.36 \\
$\quad$ Males & 4.16 & 0.70 & & & \\
Females & 4.21 & 0.56 & & & \\
LE & & & 0.89 & 505 & 0.38 \\
$\quad$ Males & 4.0 & 0.54 & & & \\
$\quad$ Females & 4.02 & 0.45 & & & \\
AOG & & & & & \\
$\quad$ Males & 4.22 & 0.59 & 1.24 & 505 & 0.22 \\
$\quad$ Females & 4.28 & 0.53 & & & \\
ENJ & & & -2.10 & 497 & 0.04 \\
Males & 3.44 & 0.77 & & & \\
Females & 3.29 & 0.85 & & & \\
MA & & & 5.17 & 491 & $<0.001$ \\
Males & 2.71 & 0.76 & & & \\
Females & 3.09 & 0.88 & & & \\
\hline \hline
\end{tabular}

We found male students scored significantly higher in enjoyment $(E N J)$ factor $(M=3.44, S D=0.77)$ than female students $[(M=3.29, S D=0.85) ; t(497)=-2.10, p<0.05]$ However, the effect size is relatively small $(\mathrm{d}=0.2)[27]$. The result suggests that male students tend to enjoy mathematics more than female students, which is in line with the findings from Lee and Yuan who found that female students enjoyed mathematics less [30]. The result of this study contradicts with the findings from a study which suggests that higher enjoyment predicted achievement [4]. It suggests that male students generally do better in mathematics as they enjoy it more. However, that is not the case in this study. Even though male students enjoy mathematics more than female students, there is no significant difference in their mathematics achievement when compared to female students.

Our study found that female students have significant higher mathematics anxiety score $(M=3.09, S D=0.88)$ than male students $[(M=2.71, S D=0.76) ; t(491)=5.17, p<0.001)]$. The effect size is 0.5 , which is moderate [27]. The result suggests that female students experience more anxiety when performing mathematics related tasks. The result is consistent with the study conducted by Hughes-Isley who found that female students scored higher on anxiety [25]. This could be due to female students exhibiting less enjoyment of mathematics than male students. Reference [31] concurs that anxiety experienced by female students could be caused by less enjoyment in mathematics. However, it is interesting to note that although female students exhibited higher mathematics anxiety than male students in this study, their achievement in mathematics were comparable. This result is in line with the findings of another study which shows that there is no statistical significant difference in mathematics performance even though female students scored higher on the mathematics anxiety scale [23]. The result of this study suggests that innovative approaches in teaching and learning to enhance positive and enjoyable learning experience is likely to reduce mathematics anxiety among students, particularly female students.

\section{CONCLUSION}

While gender's effect on student mathematics achievement was not significant, male and female enabling students have significantly different responses to affective factors such as mathematics anxiety, enjoyment of mathematics, and self-efficacy. There were no significant differences between male and female students in active learning strategies, learning environment, achievement-oriented goals and perceived usefulness of mathematics factors. Several implications can be drawn from this study. It is crucial to make changes in instructional practice to provide conducive classroom environment to promote positive attitude in mathematics, particularly increasing enjoyment and reducing mathematics anxiety among students. In addition, since our study found that there is no statistical significant difference in mathematics achievement between male and female students, female students could possibly achieve higher than male students if they develop positive attitude which evidently influence mathematics achievement. Hence, scaffolding in understanding mathematical concepts and acquiring procedural knowledge will be beneficial to female students to reduce their anxiety in mathematics classroom and enhance their self-efficacy to optimise their potential to improve mathematics achievement.

The limitation in this study is that it was restricted to students who were studying in a tertiary enabling program. A longitudinal study will be useful for future research to examine if these affective factors change over the entire period they are at the university. It will also be interesting to examine if there are significant differences between how enabling students and students who enter university through traditional pathways differ in terms of affective factors influencing mathematics learning.

\section{REFERENCES}

[1] G. M. Guy, J. Cornick, and I. Beckford, "More than math: On the affective domain in developmental mathematics," International Journal for the Scholarship of Teaching and Learning, vol. 9, no. 2, 2015.

[2] L. Bol, D. Y. Campbell, T. Perez, and C. J. Yen, "The effects of self-regulated learning training on community college students' metacognition and achievement in developmental math courses," Community College Journal of Research and Practice, vol. 40, no. 6, pp. 480-495, 2016

[3] J. Samuelsson and K. Granstrom, "Important prerequisites for students" mathematical achievement," Journal of Theory and Practice in Education, vol. 3, no. 2, pp. 150-170, 2007.

[4] D. W. Putwain, S. Becker, W. Symes, and R. Pekrun, "Reciprocal relations between students' academic enjoyment, boredom, and achievement over time," Learning and Instruction, vol. 54. pp. 73-81, 2018. 
[5] G. Brown, "Review of education in mathematics, data science and quantitative disciplines," Report to the Group of Eight Universities, Group of Eight (NJ1), 2009.

[6] G. McPhan, W. Morony, J. Pegg, R. Cooksey, and T. Lynch, "Maths? Why not?" Dept of Education, Employment and Workplace Relations, Australia Government, Canberra, 2008.

[7] C. Varsavsky, "Chances of success in and engagement with mathematics for students who enter university with a weak mathematics background," International Journal of Mathematical Education in Science and Technology, vol. 41, no. 8, pp. 1037-1049, 2010.

[8] J. Lee, "College for all: Gaps between desirable and actual P-12 math achievement trajectories for college readiness," Educational Researcher, vol. 41, no. 2, pp. 43-55, 2012.

[9] R. D. Duncan, "The relationship between math preparation in high school and math skills of entering college students," Ed.D dissertation, Graduate College, Oklahoma State University, United States, 2000.

[10] A. Beckley, "Widening participation to disadvantaged groups: one university's approach towards targeting and evaluation," International Studies in Widening Participation, vol. 1, no. 2, pp. 2-14, 2014.

[11] M. Pinxten et al., "Enjoying mathematics or feeling competent in Mathematics? Reciprocal effects on Mathematics achievement and perceived math effort expenditure," British Journal of Educational Psychology, vol. 84, pp. 152-174, 2014.

[12] L. H. Sisson, "Examining the attitudes and outcomes of students enrolled in a developmental mathematics course at a central Florida Community College," Ed. D dissertation, College of Education, University of South Florida, Florida, United States, 2011.

[13] H. L. Tuan, C. C. Chin, and S. H. Shieh, "The development of a questionnaire to measure students' motivation towards science learning," International Journal of Science Education, vol. 27, no. 6, pp. 639-654, 2005.

[14] S. Y. Lim and E. Chapman, "Development of a short form of the attitudes toward mathematics inventory," Educational Studies in Mathematic, vol. 82, no. 1, pp. 145-164, 2013.

[15] M. S. Hoyert, "Goal orientation and academic failure in traditional and nontraditional aged college students," College Student Journal, vol. 43, no. 4, pp. 1052-1061, 2009.

[16] W. Luo, S. G. Paris, D. Hogan, and Z. Luo, "Do performance goals promote learning? A pattern analysis of Singapore students' achievement goals," Contemporary Educational Psychology, vol. 36, no. 2 , pp. $165-176,2011$.

[17] T. D. Keys, A.M. Conley, G. J. Duncan, and T. Domina, "The role of goal orientations for adolescent mathematics achievement," Contemporary Educational Psychology, vol. 37, no. 1, pp. 47-54, 2012.

[18] S. Y. Lim and E. Chapman, "An investigation of the Fennema-Sherman mathematics anxiety subscale," Measurement and Evaluation in Counseling and Development, vol. 20, no. 10, pp. 1-12, 2012.

[19] B. L. Clanton, "The effects of a project-based mathematics curriculum on middle school students' intended career paths related to science, technology, engineering and mathematics," Ed.D. dissertation, College of Education, University of Central Florida, United States, 2004.

[20] W. Wang, H. Yin, G. Lu, and Q. Zhang," Environment matters: exploring the relationships between the classroom environment and college students' affect in mathematics learning in China," Asia Pacific Education Review, vol. 18, no. 3, pp. 321-333, 2017.

[21] E. L. Deci, R. J. Vallerand, L. G. Pelletier, and R. M. Ryan, "Motivation and education: The self-determination perspective," Educational Psychologist, vol. 26, no. 3-4, pp. 325-346, 1991

[22] T. Goetz, A. C. Frenzel, N.C. Hall, and R. Pekrun, "Antecedents of academic emotions: Testing the internal/external frame of reference model for academic enjoyment," Contemporary Educational Psychology, vol. 33, no. 1, pp. 9-33, 2008.

[23] A. Devine, K. Fawcett, D. Szucs, and A. Dowker, "Gender differences in mathematics anxiety and the relation to mathematics performance while controlling for test anxiety," Behavioral and Brain Functions, vol. 8 , no. 33, pp. 1-9, 2012.

[24] J. C. Nunnally and I. H. Bernstein, Psychometric Theory, 3rd ed. New York: McGraw-Hill, 1994.

[25] S. Hughes-Isley, "Differences between male and female community college students in achievement and attitude on college remedial mathematics," Ph.D. dissertation, School of Education, Colorado State University, Colorado, United States, 2015.

[26] S. M. Lindberg, J. S. Hyde, J. L. Petersen, and M. C. Linn, "New trends in gender and mathematics performance: A meta-analysis," Psychological Bulletin, vol. 136, no. 6, pp. 1123-1135, 2010.

[27] J. Cohen, Statistical Power Analysis for the Behavioural Sciences, Hillsdale. NJ: Lawrence Earlbaum Associates, 1988.

[28] C. Huang, "Gender differences in academic self-efficacy: a meta-analysis." European Journal of Psychology of Education, vol. 28 no. 1, pp. 1-35, 2013.

[29] P. D. Parker, B. Zanden, and R. B. Parker, "Girls get smart, boys get smug: Historical changes in gender differences in math, literacy, and academic social comparison and achievement," Learning and Instruction, vol. 54, pp. 125-137, 2018.

[30] C. Y. Lee and Y. Yuan, "Gender differences in the relationship between Taiwanese adolescents' mathematics attitudes and their perceptions toward virtual manipulatives," International Journal of Science and Mathematics Education, vol. 8, no. 5, pp. 937-950, 2010.

[31] D. A. Brownridge, "Gender and mathematics anxiety: An exploration of differences among university students," M.A. thesis, Dept of Sociology, Univeristyof Manitoba, Manitoba, Canada, 1994.

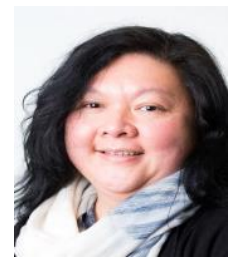

Pek Foong Ng (Jasmine Ng) was born in Malaysia in 1968. She obtained her M.Ed from University of Science Malaysia, Malaysia in 1997. She currently works at University of South Australia, Australia as a lecturer. She has presented in many international conferences in relation to education, particularly, in mathematics education in enabling programs.

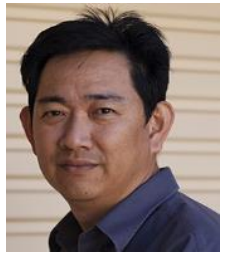

Kung-Keat Teoh was born in Malaysia in 1967 and earned his $\mathrm{PhD}$ at Multimedia University, Melaka, Malaysia in information technology in 2008. He currently works at Flinders University, Australia as a senior lecturer. He has published in various journals and presented in conferences in areas of education technologies, presence, social network, augmented reality, technology acceptance and learning analytics. 